\title{
Larvicidal Potential of Crude Methanolic Leaf Extract of Azadirachta indica On Mosquito Larvae.
}

\author{
Chombo Timothy ${ }^{a, 1,2}$
}

a College of Health Sciences, School of Biomedical Sciences Department of Pharmacology, and Therapeutics, Makerere University

\begin{abstract}
\end{abstract}

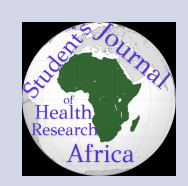

\section{Background: ${ }^{a}$}

Mosquitoes are pestiferous vectors responsible for the transmission of various dreadful diseases like malaria and yellow fever, causing millions of deaths every year. Indiscriminate use of chemical insecticides has resulted in the development of resistance by these organisms, resulting in rebounding vectorial capacity. The traditional Ugandan system of medicine mentions neem (Azadirachta Indica) to have many medicinal properties. So the present study was to assess the larvicidal ability of the aqueous extracts of ten medicinal plants against mosquito larvae.

\section{Method}

Six third and fourth instar larvae, each were introduced into treatment trays containing $15 \mathrm{ml}$ of their natural growth medium. To the treatment set, respective concentrations of the plant extracts $(0.4,0.8,1.2,1.6 \mathrm{ml})$ were added from the stock solution; maintaining a relative concentration of the plant extract as $2,4,6,8 \mathrm{mg} / \mathrm{ml}$ respectively. Control was maintained, containing only larvae and natural growth medium. Mortality counts of larvae were monitored at regular intervals i.e. 6,12 , and 24 Hours after treatment. Larvae were considered dead if they settle and remain motionless in the bottom of the test beaker with no response to light or mechanical stimulus or not recovering life functions even after being transferred to their growth medium.

\section{Results:}

It was found that the crude methanolic neem leaf extract showed significant larvicidal effect at different concentrations, hence can be safely used as a potent larvicidal agent. LC50 $=3.02 \mathrm{mg} / \mathrm{ml}$ LD90 $=33.11 \mathrm{mg} / \mathrm{ml}$. There is a strong correlation between mortalities observed in larvae and extract concentration.

\section{Conclusion and recommendations:}

As the leaf extract of Azadirachta Indica is highly toxic even at low doses this plant may eventually prove to be a useful larvicide. Further analysis is required to isolate the active principles and optimum dosages, responsible for the larvicidal activity. This plant would be eco-friendly and may serve as a suitable alternative to synthetic larvicides as they are relatively safe, inexpensive, and are readily available in many areas of the world.

\footnotetext{
${ }^{a}$ Email: chombotimothy49@gmail.com Received: 12th/12/2020 Accepted: 20th/01/2021 Journal of Pharmacology and Chemotherapeutics
} 


\section{Background}

Mosquitoes transmit serious human diseases like malaria and yellow fever causing millions of deaths every year. The use of synthetic insecticides to control vector mosquitoes has caused physiological resistance and adverse environmental effects in addition to high operational costs. Insecticides of botanical origin have been reported as useful for the control of mosquitoes. Azadirachta indica (Meliaceae) and its derived products have shown a variety of insecticidal properties (Virendra, 2009).

Malaria is one of the world's most common and severe tropical diseases. It is caused by mainly Plasmodium falciparum protozoa that are transmitted by the female Anopheles mosquitoes (Pimenta et al., 2015). Among all the anopheline mosquito species, the Anopheles gambiae is considered the most virulent. Malaria infects more than 300 million humans each year, killing approximately 1.5 to 3 million people globally each year with about $90 \%$ of all infections occurring in Africa, south of the Sahara (The African Malaria report, 2003). Malaria epidemics have devastated large populations and continue to pose a serious threat to economic progress in many developing countries (Keiser family foundation, 2007).

Estimates from the Uganda Ministry of Health show that around 16 million cases of malaria occur annually in the country, with 100,000 people dying from the disease, mostly pregnant women and children.

Despite considerable efforts to eradicate or control malaria, no effective malaria vaccine is yet available (Matasyoh et al., 2008). At the same time, the anopheles mosquitoes have developed resistance to many synthetic commercial insecticides (Okia et al., 2018). The extensive use of chemical insecticides for control of vector-borne diseases has also created problems such as adverse environmental effects, high operational cost, and community acceptance(Anne et al., 2020) which has led to increased negative public perception towards their continued usage.

Vector control is so far the most successful method for reducing incidences of mosquito-borne diseases, however, there is the emergence of widespread insecticide resistance and the potential environmental issues associated with some synthetic insecticides (ICMR, 2003). Due to the concern over the quality and safety of life and the en- vironment, the emphasis on controlling mosquito vectors has shifted steadily from the use of conventional chemicals toward alternative insecticides that are target-specific, biodegradable, and environmentally safe, and these are generally botanicals in origin. This has propelled the search for and use of eco-friendly plant-based products for the control of insects such as mosquitoes (Marta, 2011).

Larval control measures are intended to reduce malaria transmission indirectly by reducing the vector population density near human habitations. As the larvae are exclusively aquatic, their distribution is determined by the locations of suitable water bodies. Immature stages prefer slow-moving or still water in which they can stay close to the surface with their breathing orifices open to the air. Unlike some other mosquito genera, anophelines require relatively clean stagnant water for development (Nayana et al., 2013). One advantage of targeting larvae is that they cannot escape from their breeding sites until the adult stage and therefore the larvae cannot easily avoid control measures.

Currently, numerous products of botanical origin, especially the secondary metabolites, are increasingly receiving considerable worldwide attention as potentially bioactive agents used in insect vector management (Kishore et al., 2013).

Azadirachta indica is well known in Uganda and its neighbouring countries as one of the most versatile medicinal plants having a wide spectrum of biological activity. Every part of the tree has been used as traditional medicine for a household remedy against various human ailments (Kuma et al., 2013). About $80 \%$ of Ugandans still use medicinal plants to treat not only malaria but also several different illnesses and conditions. Some of these include; eczema, ringworm, acne, anti-inflammatory, antihyperglycemic properties, and it is used to heal chronic wounds, diabetic foot, and gangrene. It is believed to remove toxins from the body, neutralize free radicals and purify the blood. It is used as an anticancer agent and it has hepato-renal protective activity and hypolipidemic effects.

Neem extract has antiviral activity; almost every part of the tree has been in use since ancient times to treat several human ailments. The extract from bark, leaves, fruits, and root have been used to control leprosy, intestinal helminthiasis, and respiratory disorders in children. A leaf extract was found to lower raised levels of serum liver enzyme and paracetamol-induced liver necrosis. Hydroal- 
coholic leaf extract of Azadirachta indica caused a dose-dependent hypotensive effect and oral administration of neem leaf extract showed an anxiolytic effect. The antimalarial activities of neem seed and leaf extracts have been studied in vitro using malaria parasites. Components of the alcoholic extracts of leaves and seeds are effective in vitro against both chloroquine-resistant and sensitive strains of the malaria parasite. Recent investigations have shown that neem seed extract and its purified fractions inhibit the growth and development of asexual and sexual stages of drug-sensitive and resistant strains of the human malarial parasite P.falciparum.Some reasons being that the medicinal herbs are readily available within the community, less and mild side effects if any, easy to prepare, and cheap. Some therapeutic drugs have severe effects on different people hence the choice to use herbs. Despite the ever-increasing reports with regards to the larvicidal potentials of extracts of neem parts against known mosquito larvae, information on its growth inhibitory activity against mosquito larvae has been limited and scanty. The present research thus seeks to screen the leaf extracts of Azadirachta Indica for phytochemicals. The study will also evaluate the larvicidal potential of ethanolic leaf extracts of Azadirachta indica. The malaria vector has not been entirely eradicated despite the current vector control methods. Malaria is the leading cause of death among Ugandans accounting for over $27 \%$ of the lives of Ugandans. (Ministry of Health, 2016).

Azadirachta Indica is one of the plants with potential larvicidal activity and a lot of research has been done to assess its larvicidal activity by concentrating of its fruits and neem oil, hence the need for me to find out the larvicidal potential of crude ethanolic extract of dried leaves of Azadirachta indica, hence the need to fill up the remaining gaps.

\section{MATERIALS AND METHODS Study setting}

This experimental study was conducted mainly in the phytochemical laboratory at the Department of Pharmacology and Therapeutics at Makerere University College of health sciences Kampala.

\section{Study design}

The study design was experimental and it involved three groups of larvae, that's the experimental group and two control groups. The treatment was applied to the experimental group and the post-test was carried out on both groups to assess the effect of the treatment

\section{Plant collection and sample preparation:}

Fresh leaves of Neem (Azadirachta indica) were collected locally from Wakiso district and identified by the Botany Department; Makerere University Kampala (MUK). The voucher specimen was deposited in the herbarium unit of the Department of Botany, MUK. The plant material was air-dried in shade. The A. Indica leaf extract was then prepared by grounding $50 \mathrm{~g}$ of leaves using mortar and pestle, and the yield was successively soaked by $80 \%$ methanol for about 72 hours, with daily filtration and evaporation. The solvent was evaporated under reduced pressure to dryness using a rotary evaporator apparatus of the model $\mathrm{BUCHI}$ R205 to produce a final concentration of $1 \mathrm{mg} / \mathrm{ml}$. The extracts were kept in a tightly closed bottle in a refrigerator until used for anti-malarial testing to maintain their potency. Filtration and extraction were carried out in the Laboratory at the Department of Pharmacology, Makerere University College of health sciences. The pulverized material was then weighed using an analytical weighing scale of kern and Sohn Gmb HD-72336 and weight recorded.

Determination of percentage yield of extract Weight of pulverized plant material: $1 \mathrm{~kg}$ Weight of extract (g);

Weight of extract $(g)=$ weight of container $(g)+$ extract - weight of container (g)

Weight of container + extract $=61.48 \mathrm{~g}$

Weight of container $=45.68 \mathrm{~g}$

Weight of extract $(g)=61.68-45.68$

$$
=15.8 \mathrm{~g}
$$

The percentage yield of extract was $1.58 \%$

\section{Larvae}

Mosquito Culture Fourth instar larvae were collected from stagnant water areas to start the colony, and larvae were kept in plastic cups containing tap water. They were maintained and the experiments were carried out at $27 \pm 2^{\circ} \mathrm{Cand} 75$ to $85 \%$ relative humidity under $14: 10$ light and dark cycles. Larvae were fed with a diet of brewer's yeast and biscuits.

\section{Voucher specimen preparation.}

The specimen was pressed in a plant press which consists of a wooden frame with corrugated cardboard ventilators. Blotted paper and folded paper 
typically newspapers the plant press was tightened using straps with buckets.

After pilling up several units, the stack was filled with plants and made as even as possible.

Botanical identification was done by use of a dichotomous key and by comparing it with another specimen in the herbarium. The specimen was then mounted on a special paper with glue by sewing them.

Once the plant species were identified, the labels were put indicating date and site of collection (could include longitude, latitude, and altitude), name of the collector, collection-number, species, and botanical family of plant.

This was done and deposited in the herbarium unit of the Department of Botany, Makerere University Kampala.

\section{Chemicals.}

All chemicals used in this study were of analytical grade. They were products of May and Baker, England and Merck, Darmstadt, Germany.

\section{Phytochemical tests.}

Preliminary phytochemical tests were carried out on the hydroalcoholic extract of neem leaves using the methods of Harbone(1984) and Trease and Evans (1989). Tests for the presence or absence of phytochemical compounds using the above methods involving the addition of an appropriate chemical agent to the extract of the plant in a test tube. The mixture was shaken vigorously or gently as the case may be. The presence or absence of phytochemicals such as saponins, alkaloids, tannins, etc. was observed.

\section{Test for Alkaloids (General test)}

Sulphuric acid (20 $\mathrm{ml}$ of $5 \%$ ) in $50 \%$ methanol was added to about $2 \mathrm{~g}$ of the extracted sample and heated on a boiling water bath for $10 \mathrm{~min}$, cooled, and filtered. Filtrate $(2 \mathrm{ml})$ was tested with a few drops of Mayer's reagent (Potassium mercuric iodide solution), Dragendorff's reagent (Bismuth potassium iodide solution), Wagner's reagent (Iodide in potassium iodide solution), and Picricacid solution (1\%). The remaining filtrate was placed in a $100 \mathrm{ml}$ separating funnel and made alkaline with dilute ammonia solution. The aqueous alkaline solution was separated and extracted with two $5 \mathrm{ml}$ portions of dilute sulphuric acid. The sample was tested with a few drops of Mayer's, Wagner's, and Dragendorff's reagent.

Test for glycosides. (Fehling's test)
A quantity of $5 \mathrm{ml}$ of a mixture of equal parts of Fehling's solution I and II were added to $5 \mathrm{ml}$ of the extracted sample and then heated on a water bath for 5 min.

\section{Test for saponins. (Fehling's method)}

Water $(20 \mathrm{ml}$ ) was added to $0.25 \mathrm{~g}$ of the extract in a $100 \mathrm{ml}$ beaker and boiled gently on a hot water bath for $2 \mathrm{~min}$. The mixture was filtered hot and allowed to cool and the filtrate was used for the following test: Fehling's Test: To $5 \mathrm{ml}$ of the filtrate was added $5 \mathrm{ml}$ of Fehling's solution (equal parts of I and II) and the content heated. A reddish precipitate indicated the presence of saponins. It was then heated further with sulphuric acid.

\section{Test for Flavonoids. (Ammonium method)}

Ethyl acetate $(10 \mathrm{ml})$ was added to $0.2 \mathrm{~g}$ of the extracted sample and heated on a water bath for 3 min. The mixture was cooled, filtered and the filtrate used for the Ammonium test: About $4 \mathrm{ml}$ of the filtrate was shaken with $1 \mathrm{ml}$ of dilute ammonia solution, and layers left to separate.

\section{Test for Steroids and terpenoids.}

Ethanol (9ml) was added to $1 \mathrm{~g}$ of the extracted sample and refluxed for a few minutes and filtered. The filtrate was concentrated to $2.5 \mathrm{ml}$ on a boiling water bath and $5 \mathrm{ml}$ of hot water added. The mixture was allowed to stand for $1 \mathrm{~h}$ and the waxy matter filtered off. The filtrate was extracted with $2.5 \mathrm{ml}$ of chloroform using a separating funnel. To $0.5 \mathrm{ml}$ of the chloroform extract in a test, the tube was carefully added to $1 \mathrm{ml}$ of concentrated sulphuric acid to form a lower layer.

\section{Assessment of the larvicidal effect \\ Preparation of test concentrations}

According to WHO guidelines (2005). The stock solution was prepared by dissolving 2 grams of the solid neem leaf extract in $15 \mathrm{ml}$ of distilled water. The stock solution was then serially diluted

Test volumes were prepared into final concentrations by picking $(0.4,0.8,1.2,1.6 \mathrm{mg} / \mathrm{ml})$ using pipettes with disposable tips; the concentrations were topped up to $15 \mathrm{ml}$ using distilled water, the lowest concentration was prepared first through single dilution method and stored in labeled specimen $20 \mathrm{ml}$ test tubes for a few minutes before being used for larvicidal bioassay. extract., first. Small volumes of dilutions were transferred to test cups.

\section{Larvicidal bioassays}

Bioassay for the larvicidal activity was carried out using the WHO procedure (2005) with minor modifications. 
Six larvae, from the breeding container, were picked using a dropper into treatment trays containing $15 \mathrm{ml}$ of their natural growth medium (Tap water - untreated - added with dog biscuits and yeast).

To the treatment set, respective concentrations of the plant extracts $(0.4,0.8,1.2$, and $1.6 \mathrm{mg} / \mathrm{ml})$ were added from the stock solution; maintaining a relative concentration of the plant extract as $2,4,6$, and $8 \mathrm{mg} / \mathrm{ml}$ respectively. Control was maintained, containing only larvae and natural growth medium.

Mortality counts of larvae were monitored after 24Hours from Treatment. Larvae were considered dead if they settle and remain motionless in the bottom of the test beaker with no response to light or mechanical stimulus or not recovering life functions even after being transferred to their growth medium.

The percentage mortality was calculated by using the formula (1), and corrections for mortality when necessary were done using Abbot's (1925) formula (2)

\section{Percentage of Mortality}

Number of dead larvae $\times 100$

Number of larvae introduced

Corrected percentage of mortality

1 - $\mathrm{n}$ in $\mathrm{T}$ after treatment $\times 100$

\subsection{In C after treatment}

Where $\mathrm{n}=$ number of larvae or nymph, $\mathrm{T}=$ treated, $\mathrm{C}=$ control.

LC50 and LC90 values, confidence intervals were determined by the probit analysis method as described by Finney (1971).

Before plotting, the percentages of the dead larvae are calculated and are then corrected.

The $\%$ mortality was converted to Probits (short for probability unit) by looking up those corresponding to the \% responded in Finney's table

The probit values were then plotted against log doses, and then the dose corresponding to probit $5(50 \%)$ was found out to be the LC50 which represents the concentration (LC50) at which $50 \%$ of the population responds and the probit $9(90 \%)$ was found out to be the LC90.

Approximate S.E of Ic50 $=(\log |\mathrm{lc} 84-\log | \mathrm{c} 16) / \sqrt{ } 2 \mathrm{~N}$

$\mathrm{Nis}$ the total number of larvae employed in different groups. The log values are obtained from the line on the graph corresponding to probits 6 and 4.

\section{Ethical considerations}

The purpose of the research was to determine the larvicidal potential of Azadirachta indica leaves, this was to contribute to the knowledge and development of newer larvicides used in controlling malaria.

This research and experimental procedures were approved by the Department of Pharmacology and Therapeutics in the College of Health Sciences, Makerere University Kampala.

\section{Data management and quality control. Pre-testing of data collection tools.}

The study being laboratory-based, the research had to ensure that the laboratory equipment to be used had validity and the reagents were not expired through calibration or equipment and checking for expiry dates of reagents.

\section{Data management}

The data obtained during the studies was first recorded manually in logbooks that were locked up in lockers in the laboratory for security purposes and then later transferred to computers and were kept under strict privacy and confidentiality in a password secured computer to prevent unnecessary access of the information.

\section{Data analysis}

The concentration at which mortality was observed ( $\mathrm{mg} / \mathrm{ml}$ ) was corrected using Abbott's formula. Statistical analysis of the experimental data was performed with MS Excel 2007 to find the Standard Deviation and LC50 using Probit Analysis.

\section{Study limitations}

The researcher was financially restricted since the study was not funded. This being an experimental study the time given was not sufficient for a proper experimental study. However, the researcher had to do everything possible to overcome the above-mentioned obstacles to obtain the study results.

\section{Percentage yield.}

\section{RESULTS}

The percentage yield of extract was $1.58 \%$

\section{Larvicidal activity}

The mortality percentages of mosquito larvae noticed are depicted in Table 2.

Figure $1 \mathrm{~A}$ graph of Probits versus Log dose

A dose-response relationship was determined for Azadirachtin applied for $24 \mathrm{~h}$ to newly ecdysed third and fourth instar larvae. With probit, the LC50 
Thile 3.2 Tranaformation of percentage to prolut

\begin{tabular}{|c|c|c|c|c|c|c|c|c|c|c|}
\hline 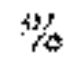 & 0 & 1 & 2 & 3 & 4 & 5 & 6 & 7 & 8 & $\theta$ \\
\hline$\theta$ & 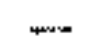 & 2,64 & 2.95 & 3.12 & $3.8 \pi$ & 8.30 & 3.45 & 3.52 & $3.5 \mathrm{~g}$ & 3,06 \\
\hline $10^{\circ}$ & 3.72 & 77 & S $8 \mathrm{~A}$ & 3.87 & 3.92 & 3.90 & 401 & 4.05 & 4.08 & 1.12 \\
\hline 20 & 4.90 & 4.19 & 4.23 & 4.20 & 4.80 & 4.33 & 4.40 & 4.34 & $4,4 \dot{2}$ & 4.45 \\
\hline 30 & 4.48 & 4,56 & 4.6.5 & 4,$5 ;$ & 4.60 & 4.53 & $4: 94$ & 4.67 & 4,99 & 4.72 \\
\hline 40 & 4.75 & 4.77 & 4.80 & 4.82 & 4.85 & 4.87 & 4.90 & 4.82 & 4.85 & 4.97 \\
\hline 50 & 5.00 & 6,03 & 5.95 & 5.08 & 5. 10 & 5.18 & 8. 15 & s.1s & 5.26 & 5.213 \\
\hline 60 & 5.25 & E. & G.31 & 5.37 & 5.30 & 5.30 & 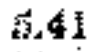 & 5.44 & 5.47 & 5.50 \\
\hline 70 & $\pi .82$ & $6.5 \%$ & 5. & tiffl & 6.04 & 5.87 & $5+71$ & 5.74 & 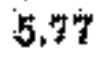 & 5.81 \\
\hline 80 & 5.84 & 8.89 & 3.92 & 5.98 & $\mathbf{5 . 9 0}$ & 6,04 & $3.0 \mathrm{~B}$ & 6. 13 & 0.18 & 6i:23 \\
\hline $10 y$ & $6,2 \mathrm{~S}$ & 1.94 & $0,4,1$ & [i.4. & 6.56 & .9 .94 & 0.76 & $6.6 \mathrm{~s}$ & 7.05 & $7: 33$ \\
\hline$\therefore$ & $\$ 0$. & 0.1 & 0.2 & 0.3 & 0.4 & 0.6 & $0: 6$ & f.7 & 0.8 & 0.0 \\
\hline 09 & 7.33 & $T .37$ & 7.41 & 3.46 & $T .51$ & 7.58 & 7,00 & 7.7. & $\cdot \pi, \$ 8$ & 8.00 \\
\hline
\end{tabular}


Table 1. Larvicidal activity of Azadirachtin at various concentrations applied for $24 \mathrm{~h}$ to newly ecdysed third and fourth instar

\begin{tabular}{llllllll}
\hline Group & $\begin{array}{l}\text { Number of mosquito } \\
\text { larvae }\end{array}$ & Dose $(\mathrm{mg} / \mathrm{ml})$ & $\begin{array}{l}\text { Log } \\
\text { dose }\end{array}$ & $\begin{array}{l}\text { Dead } \\
\text { larvae }\end{array}$ & $\begin{array}{l}\text { Mortality } \\
(\%)\end{array}$ & $\begin{array}{l}\text { Corrected } \\
\%\end{array}$ & $\begin{array}{l}\text { Pro- } \\
\text { bits }\end{array}$ \\
2 & 6 & 2 & 0.3 & 2 & 33.3 & 33.3 & 4.56 \\
4 & 6 & 4 & 0.6 & 4 & 66.6 & 66.6 & 5.41 \\
6 & 6 & 6 & 0.78 & 5 & 83.3 & 83.3 & 5.98 \\
8 & 6 & 10 & 1 & 6 & 100 & 97.5 & 6.96 \\
\hline
\end{tabular}

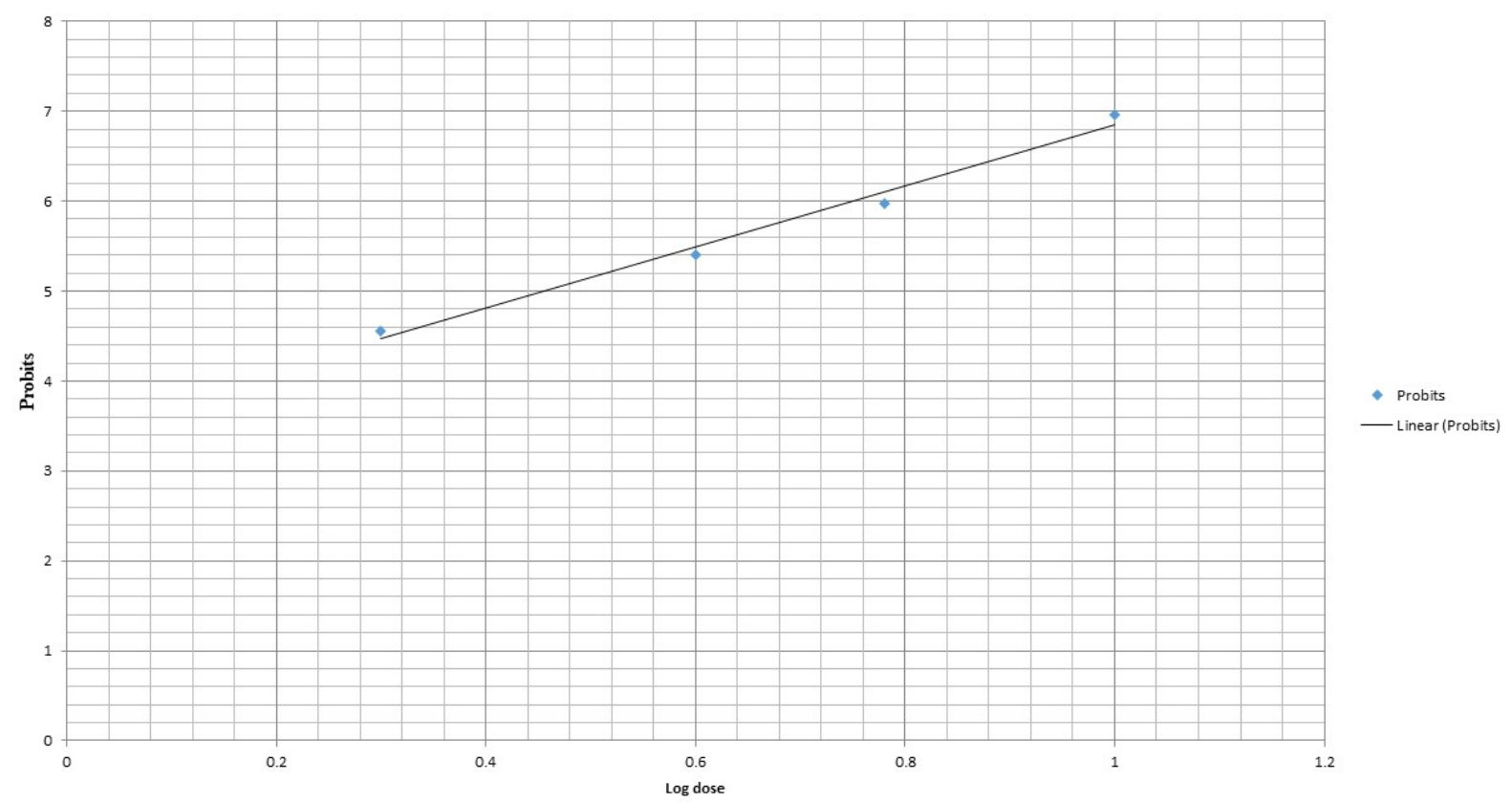

Chart 1. A graph of Probits versus Log dose

was calculated as $3.02 \mathrm{mg} / \mathrm{ml}$ and the LC90 was $6.02 \mathrm{mg} / \mathrm{ml}$, (Table3). The highest concentration caused $100 \%$ mortality (Table 2 ), and the least concentration caused $33.3 \%$ mortality.

\section{Phytochemical tests.}

The results for the various tests carried out are shown in table 1

Key

+ present

- absent

The Azadirachta Indica leaf extract contained, Saponins, reducing sugars, Alkaloid salts, Flavonones, Anthraquinones, and Tannins but no steroid glycosides.
The results reveal that the plant extracts owing to their phytochemical constituents may give the reported pharmacological activities.

\section{DISCUSSION.}

\section{Larvicidal activity}

Azadirachtin, the extract of the neem tree, was tested in the present study. It is proved that crude or partially-purified plant extracts are less expensive and highly efficacious for the control of mosquitoes rather than the purified compounds or extracts.

The experimental results obtained from this study revealed that all $A$. indica extracts showed 
Table 2. Results for phytochemical tests on theAzadirachta Indica leaf extract.

\begin{tabular}{ll}
\hline Plant constituents & Availability \\
Saponins & + \\
Tannins & + \\
Steriod glycosides & - \\
Reducing sugars & + \\
Alkaloids & + \\
Flavinoids & + \\
Anthraquinones & + \\
\hline
\end{tabular}

larvicidal activity against Anopheles mosquito larvae a finding that is similar to a previous study by Ghosh et al., (2013). The larvicidal activity among extracts was extremely broad. The various biological activities of these plant extracts may be due to various phytochemical classes, existing in the plant; these compounds may jointly or independently contribute to producing larvicidal activity. The negative control used was water which has no effect on the mosquito larvae and showed a normal response.

The data showed that larvicidal effect rose gradually with an increase in dose until it reached a peak of $100 \%$ mortality after $6 \mathrm{mg} / \mathrm{ml}$ of the extract, a finding that is in agreement with a study by Kajla et al., (2016). Beyond this dose the larvicidal effect observed was constant until the highest concentration of $20 \mathrm{mg} / \mathrm{ml}$. The LC50 value for the methanolic extract was $3.02 \mathrm{mg} / \mathrm{ml}$, while the LC90 value was $33.11 \mathrm{mg} / \mathrm{ml}$ for $24 \mathrm{~h}$.

The growth regulatory effect is the most important physiological effect of $M$. azedarach on insects. It is because of this property that the family Meliaceae has emerged as a potent source of insecticides. Exposure of mosquito larvae to sub-lethal doses of neem leaves extract in the laboratory prolonged larval development, reduced pupal weight, and oviposition The results of this study will contribute to a great reduction in the application of synthetic insecticides, which in turn will increase the opportunity for natural control of various medicinally important pests by botanical pesticides. Since these are often active against a limited number of species including specific target insects, less expensive, easily biodegradable to non-toxic products.

\section{Phytochemical tests.}

Results have shown that plant origin extracts contain active phytochemicals, a find that is agreement with a study by serunjogi et al., (2020), were saponins, Tannins, Steriod glycosides, Alkaloids, and Flavonoids were confirmed present in the plant origin extracts. These have activity against the mosquito lavae.

\section{CONCLUSION AND RECOMMENDATIONS}

\section{Conclusion}

As the leaf extract of Azadirachta Indica is highly toxic even at low doses this plant may eventually prove to be a useful larvicide. Further analysis is required to isolate the active principles and optimum dosages, responsible for the larvicidal activity. The product of this plant can as well be utilized for preparing biocides or phytochemicals from which the non-target organisms can be rescued from harmful vectors. This plant would be ecofriendly and may serve as a suitable alternative to synthetic larvicides as they are relatively safe, inexpensive, and are readily available in many areas of the world.

\section{Recommendations}

It is the recommendation of this work that these compounds can be investigated further for product development. Repeated bioassay coupled with analytical fractionation is needed to confirm the actual active compounds responsible for the larvicidal activity of Azadirachta Indica. More advanced purification techniques such as HPLC and 13C NMR should be applied to maximize the yield and structural confirmation. The mode of action of the active compound, as well as its possible effects on the non-target organism, should be studied before it can be practically used as a natural mosquito control agent. The products of this research should be synthesized to confirm their structure and be recommended as a candidate for formulations as 
a larvicide. Therefore, further study should be carried out to test the larvicidal potential against a different type of mosquito species larvae with a different formulation of extract, the dosage level, mode of action, and synergism with the biocides under field condition are needed.

\section{Limitations of the study}

. Lack of availability or access to literature needed was a major problem faced during the literature review.

. The reagents and materials required for laboratory work were expensive and not readily available hence this limited the study. Access to mosquito larvae was also a major limitation due to weather changes

- Idiosyncratic reactions among the mosquito larvae could have led to less accurate results. Individual variations in response to the drug were therefore a major challenge.

. The process involved in data analysis using MS EXCEL, SPSS software, and one-way ANOVA was very expensive and not easily accessible.

\section{Acknowledgment.}

My deepest and heartfelt gratitude goes to the Lord Almighty for $\mathrm{He}$ is the reason for all these happenings of life. I would like to first thank my parents Mr. Eremu John Paul and Mrs. Eremu Lucy and the entire family for the moral and financial support they extended towards my education. My special thanks go to Mr. Odia Gordon and Mr. Lubega Aloysius for the technical support they offered when carrying out my research.

Special thanks also go to Mr. Kimbowa Isaac for devoting his time in guiding me as my supervisor throughout the research period.

Finally, I would like to express my deep appreciations and gratitude to all my Friends Ddumba Trevor, Mawejje Francis, Kalule Musa, Kyamugeni Amir, Naluyima Sandra, Nakabugo Elizabeth, and others not included, Lecturers, well-wishers and all individuals that have in one way or another contributed to my academic excellence, spiritual and personal growth.

\section{A References:}

1). Al-Sharook $Z$, Balan $K$, Jiang $Y, \&$ Rembold $H$, (1991). Insect growth inhibitors from two tropi- cal meliaceae. Effect of crude seed extracts on mosquito larvae. J. Appl. Ent. 111, 425-430.

https://doi.org/10.1111/j.1439-0418.1991.tb003 44.x

2). Dua, V.K., Pandey, A.C., \& Raghavendra, K. (2009) Larvicidal activity of neem oil (Azadirachta indica) formulation against mosquitoes. Malar $\mathrm{f} 8$, 124.

\section{https://doi.org/10.1186/1475-2875-8-124}

3). FOMH (2008). Malaria control in Nigeria; A strategy for behavior change communication in the roll back malaria programme in Nigeria. Publication of Roll Back Malaria Secretariat, National Malaria Control Programme, Department of Department of Public Health, Federal Ministry of Health Abuja

4). Ghosh, A., Chowdhury, N., \& Chandra, G. (2012). Plant extracts as potential mosquito larvicides. The Indian journal of medical research, 135(5), 581-598.

5). Gunathilaka, N., Fernando, T., Hapugoda, M., Wickremasinghe, R., Wijeyerathne, P., \& Abeyewickreme, W. (2013). Anopheles culicifacies breeding in polluted water bodies in Trincomalee District of Sri Lanka. Malaria journal, 12, 285. https://doi.org/10. 1186/1475-2875-12-285

6). Jang YS, Kim MK, Ahn YJ, \& Lee HS.(2002). Larvicidal activity of Brazilian plants against Aedes. aegypti and Culex pipiens pallens (Diptera: Culicidae). Agric. Chem. Biotechnol. 44, 23-26

7). Kajla, M., Bhattacharya, K., Gupta, K., Banerjee, U., Kakani, P., Gupta, L., \& Kumar, S. (2016). Identification of the Temperature Induced Larvicidal Efficacy of Agave angustifolia against Aedes, Culex, and Anopheles Larvae. Frontiers in public health, 3, 286. https://doi.org/10.3389/fpubh.2015. 00286

8). KFF (Kaiser Family Foundation). The U.S. government and global polio efforts. 2016. [March 10, 2017]. http://www.kff.org/global-health-policy/f act-sheet/the-u-s-government-and-global-polio-ef forts.

9). Kishore, N., Mishra, B.B., \& Tiwari, V.K. (2014). Natural products as leads to potential mosquitocides. Phytochem Rev 13, 587-627 (2014). https:// doi.org/10.1007/s11101-013-9316-2

10). Kumar, V. S., \& Navaratnam, V. (2013). Neem (Azadirachta indica): prehistory to contemporary medicinal uses to humankind. Asian Pacific journal of tropical biomedicine, 3(7), 505-514. https://doi. org/10.1016/S2221-1691(13)60105-7 
11). Leonardo L., Rakiswendé S. L., Giulio L., Luciano P., Fulvio E A., \& Habluetzel L. (2010) Malaria Journal 2010, 9:66

12). Maia, M.F., Moore, S.J. Plant-based insect repellents: a review of their efficacy, development and testing. Malar J 10, S11 (2011). https://doi.org/ 10.1186/1475-2875-10-S1-S11

13). Matasyoh, J.C., Dittrich, B., Schueffler, A. et al. Larvicidal activity of metabolites from the endophytic Podospora sp. against the malaria vector Anopheles gambiae. Parasitol Res 108, 561-566 (2011). https://doi.org/10.1007/s00436-010-20981

14). Ministry of Health, 2016, Malaria Bulletin, National Malaria Control Program.

15). Okia, M., Hoel, D.F., Kirunda, J. et al. Insecticide resistance status of the malaria mosquitoes: Anopheles gambiae and Anopheles funestus in eastern and northern Uganda. Malar J 17, 157 (2018). https://doi.org/10.1186/s12936-018-22936

16). Pimenta, P. F., Orfano, A. S., Bahia, A. C., Duarte, A. P., Ríos-Velásquez, C. M., Melo, F. F., Pessoa, F. A., Oliveira, G. A., Campos, K. M., Villegas, L. M., Rodrigues, N. B., Nacif-Pimenta, R., Simões, R. C., Monteiro, W. M., Amino, R., Traub-Cseko, Y. M., Lima, J. B., Barbosa, M. G., \& Lacerda, M. V. (2015). An overview of malaria transmission from the perspective of Amazon Anopheles vectors. Memorias do Instituto Oswaldo Cruz, 110(1), 23-47. https://d oi.org/10.1590/0074-02760140266

17). Serunjogi, D. (2020).The Active phytochemicals present in the Guava Tree (Psidium Guajava) leaf Extracts. Student's Journal of Health Research Africa, 1(12), 6. https://doi.org/10.51168/sjhrafrica. v1i12.12

18). The African Malaria Report. (2013). "The burden of malaria in Africa." https://www.againstmala ria.com/downloads/RBMBurdenMalariaAfrica.pdf

19). WHO (2004). Strategies framework for malaria prevention and control during pregnancy in the African region. Volume 01. Congo Brazzaville: WHO Regional office for Africa.

20). Wilson AL, Courtenay O, Kelly-Hope LA, Scott TW, Takken W, \& Torr SJ, (2020) The importance of vector control for the control and elimination of vector-borne diseases. PLoS Negl Trop Dis 14(1): e0007831. https://doi.org/10.1371/journal.pntd.0 007831 